FEREIDOON OWFI (৫ orcid.org/0000-0003-0852-4856) Iranian Fisheries Science Research Institute, Tehran, Iran

MAJID ASKARI HESNI (৫ orcid.org/0000-0001-9309-2212)

Shahid Bahonar University of Kerman, Kerman, Iran

DAVID A. EBERT (® orcid.org/0000-0003-4604-8192) Pacific Shark Research Center, Moss Landing Marine Laboratories, Moss Landing, USA, and South African Institute for Aquatic Biodiversity, Grahamstown, South Africa

This is an Open Access article, distributed under the terms of the Creative Commons Attribution licence CC BY 4.0.

\section{An additional threat to the recently rediscovered Nubian flapshell turtle in South Sudan}

The Nubian flapshell turtle Cyclanorbis elegans (Trionychidae) is one of the largest freshwater chelonians in Africa, formerly widespread across the waterbodies of the savannah regions of Ghana, Togo, Benin, Nigeria, Cameroon, Central African Republic, Chad, Sudan and South Sudan. Cyclanorbis elegans is categorized as Critically Endangered on the IUCN Red List, but no wild individuals had been recorded for decades until it was rediscovered in 2017 in South Sudan. Fishing bycatch and collection of eggs and nesting females for domestic subsistence appear to be the main threats to this species.

In 2020, along the White Nile River and its tributaries in Central Equatoria State of South Sudan, we interviewed $>300$ local fishermen about this species. We obtained information (confirmed by photographs) that four C. elegans

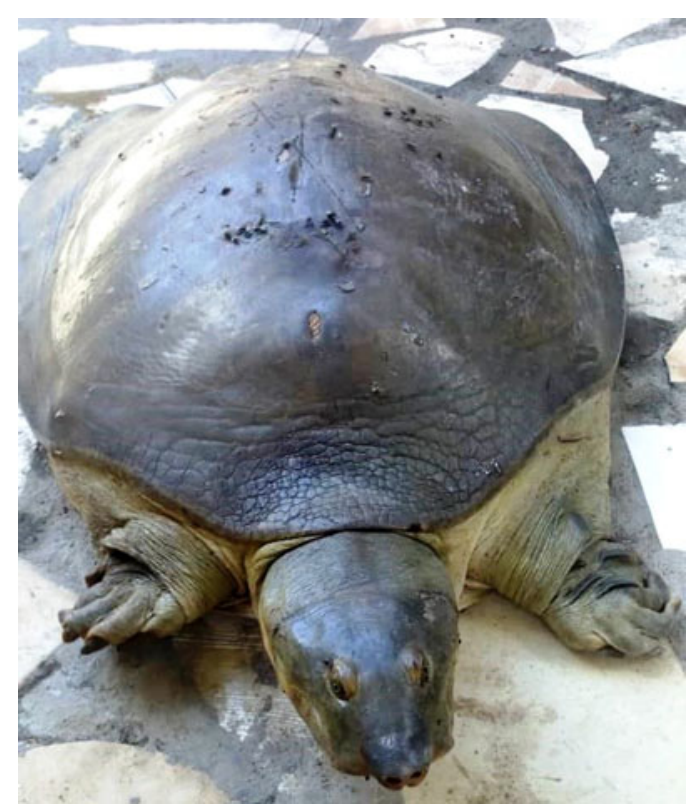

Cyclanorbis elegans captured from the surroundings of Mongalla, South Sudan. Carapace length was $63.4 \mathrm{~cm}$. captured around Mongalla (three females captured on 11 and 15 September and 22 November 2020, and a male captured on 16 December 2020) were sold by local fishermen to expatriate Chinese residents, who appear to be the main market for this turtle, paying high prices (EUR 250-400 for large individuals) for food and, in one case, for 'religious veneration'. These prices are a strong incentive for the impoverished fishing communities along the White Nile River to catch these turtles. Interviewees also suggested that expatriate Chinese may export the turtles to Asia for the food trade. Considering that the population size of this species is small, this additional threat could push the species towards extinction. The Nubian flapshell turtle appears to be extinct throughout the rest of its African range. We recommend the creation of a protected area for this species and monitoring and mitigating the potential detrimental effects that the Asian export market may have on this species.

LuCA LUISELLI (৫ orcid.org/0000-0001-6878-2916) and DANIELE DENDI (৫ orcid.org/0000-0003-1417-9091) Institute for Development, Ecology, Conservation and Cooperation, Rome, Italy.E-mail l.luiselli@ideccngo.org

John SeBit Benansio Alliance for Environment and Rural Development, Juba, South Sudan

Gift Simon Demaya Department of Wildlife Science, University of Juba, South Sudan

CRAIG B. STANFORD Department of Biological Sciences, University of Southern California, Los Angeles, USA, and IUCN Species Survival Commission Tortoise and Freshwater Turtle Specialist Group

This is an Open Access article, distributed under the terms of the Creative Commons Attribution licence CC BY 4.0 .

\section{Call for holistic, interdisciplinary and multilateral management of human-wildlife conflict and coexistence}

Conflicts over wildlife are becoming more frequent, widespread and increasingly relevant among conservation challenges and within the UN Convention on Biological Diversity's 2050 Vision of 'Living in harmony with nature'. Although the Post-2020 Global Biodiversity Framework envisages a world in which environmental conflicts are reduced, managing human-wildlife conflict and coexistence is an ongoing and complex challenge for communities and governments alike. Each situation is different, with its own history and unique complications, limiting the transferability of solutions. Effective methods to mitigate and manage these situations are elusive or are often not implemented in a socially or economically sustainable way. 